\title{
trans-Selective Hydroboration of Internal Alkynes Catalyzed by Ruthenium
}

\section{Category}

Metal-Catalyzed

Asymmetric

Synthesis and

Stereoselective

Reactions

\section{Key words}

hydroboration

trans-selectivity

ruthenium

SYNFACTing

(up to $5 \mathrm{mmol}$ scale)

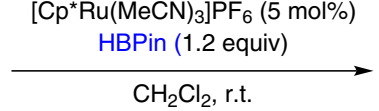

$\mathrm{R}_{\mathrm{R}^{1}}^{\mathrm{H}}=<_{\mathrm{BPin}}^{\mathrm{R}^{2}}$

23 examples

up to $94 \%$ yield

up to $98: 2 E / Z$-selectivity
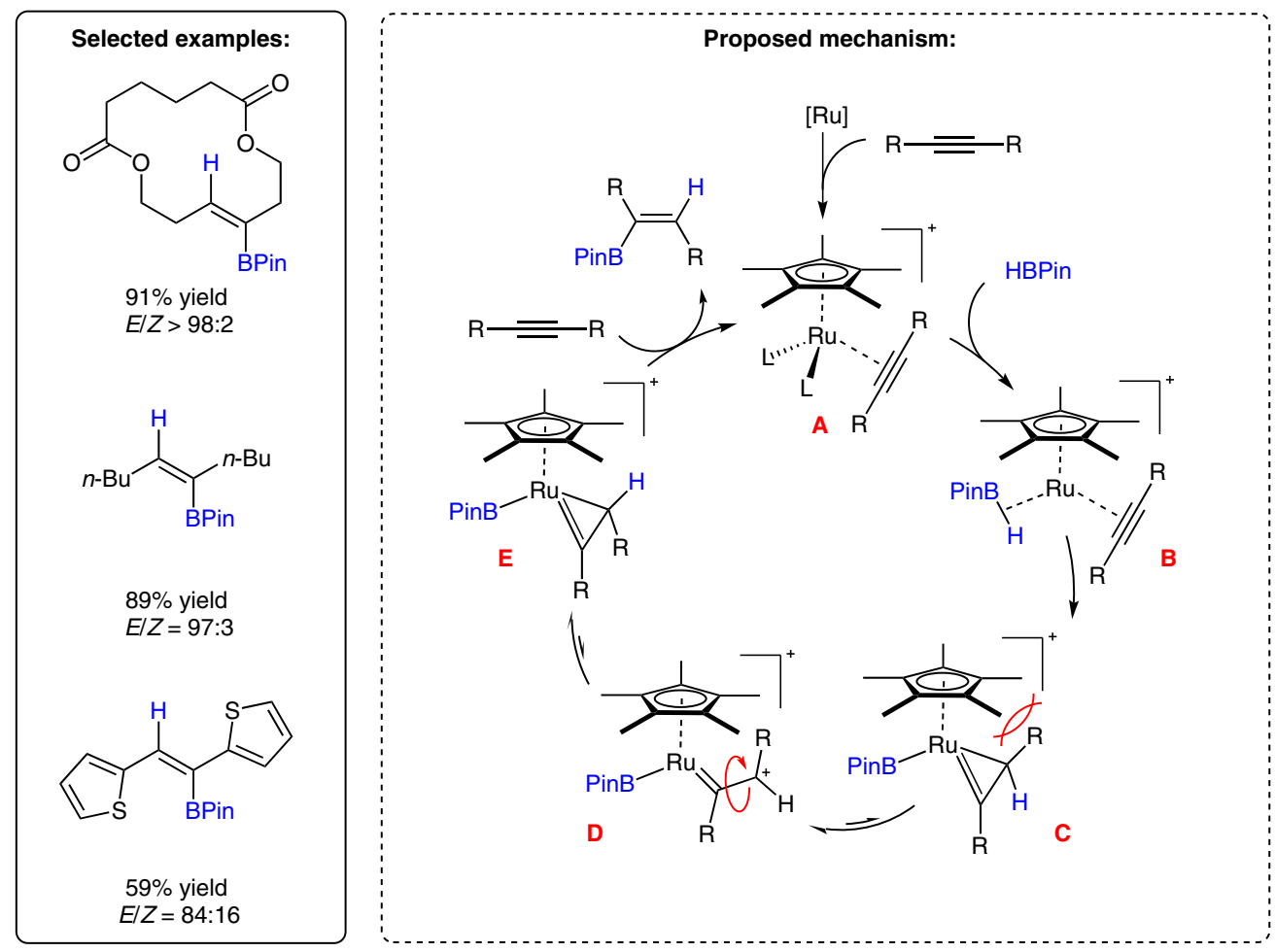

Significance: Transition-metal-catalyzed hydroboration of alkynes is a reliable method for the synthesis of $Z$-alkenes due to the stereospecific requirement for syn addition of the $\mathrm{B}-\mathrm{H}$ bond. Although access to the $E$-stereoisomer would be highly useful, transition-metal-catalyzed examples featuring trans-selective hydroboration necessitate the use of terminal alkynes (N. Miyaura and co-workers J. Am. Chem. Soc. 2000, 122, 4990; F. Pan, W. Leitner and co-workers J. Am. Chem. Soc. 2012, 134, 14349). Herein, the authors report a highly trans-selective ruthenium-catalyzed hydroboration of internal alkynes.
Comment: Both control and deuterium-labelling experiments provide support for a true trans-selective hydroboration, rather than an isomerization process. The proposed mechanism involves an inner-sphere hydride delivery to furnish metallocyclopropene $\mathbf{c}$, which can relieve steric congestion about the $\mathrm{Cp}^{\star}$ ring via isomerization to metallocyclopropene $\mathbf{E}$. The reductive elimination places the boron atom anti to the hydrogen atom, providing access to the E-configured olefin. While the method is highly functional-group-tolerant, modest regioselectivity is observed with unsymmetrical alkynes.

SYNFACTS Contributors: Mark Lautens, Christine M. Le 